\title{
Setting the record straight on the Survey of Scholars
}

\author{
By Herbert C. Morton
}

Director

Office of Scholarly Communication

and Technology

\author{
and Anne Jamieson Price \\ Staff Associate \\ Office of Scholarly Communication \\ and Technology
}

\section{A response to "The ACLS Survey and Academic Library Service."}

W are indebted to Ronald Epp and JoAn Segal for spelling out some of the implications for librarians of the ACLS Survey of Scholars (C\&RL News, February 1987), but we disagree with some of their criticisms, and are troubled by others that either miss the mark or are dead wrong-including the attribution to us of statements that appear nowhere in our text. (The survey was conducted by the Office of Scholarly Communication and Technology, 1) to gather data about humanists and social scientists as producers and users of scholarly materials and 2) to obtain their views on a wide range of issues, such as library service, applications of new technology, and academic matters related to scholarly communication, such as peer review. A preliminary report of the findings appeared in the Summer 1986 issue of our newsletter, Scholarly Communication.)

Like Epp and Segal, we will reserve our bouquets for the end, and we will begin directly with our rejoinder. Their criticisms fall mostly under two headings: that we slighted "areas of critical importance to the library community" and that we misinterpreted our own data.

\section{Half full or half empty}

Epp and Segal criticize us "for analyzing minority responses" rather than the majority, as if this were evidence of deception. The first example they cite is a passage where we report that a substantial minority of respondents say they rarely find an article worth reading in their discipline's major journal (the percentage ranges from $19 \%$ to $43 \%$, depending on the discipline). They indicate that we should have stressed that the majority of respondents do find an article worth reading in their discipline's major journal.

We disagree, though we acknowledge that this is a matter on which opinions may differ. The decision to use the "minority" response is conventional practice whenever the minority number is more relevant and more significant. For example, the Bureau of Labor Statistics puts the emphasis on the unemployment rate, even though well over $90 \%$ of the labor force has been at work since World War II. The unemployment rate is a much more revealing and more sensitive indicator of changes in the level of economic activity and of the welfare of workers in the labor force. Closer to home, educators and librarians are campaigning against illiteracy by citing the large minority of adults who are functionally illiterate rather than the larger percentage who read and comprehend.

We cite the minority figures in a number of instances when we think it is appropriate to do so. Thus, given the concern of journal editors with stagnant or declining circulation, we thought it 
more important to identify trouble spots. Similarly, we report that $20 \%$ of the respondents say that informal prepublication distribution of materials is at least as important as material in journals - a finding that has aroused a good deal of interest because it was widely believed that this practice was largely limited to scientists.

We also noted that a large minority of all respondents found the book collections in their libraryand to a lesser extent their journal collectionsinadequate for their research needs. To be sure, most respondents are satisfied with all aspects of library collections, but if librarians are concerned about improving their support of scholarship, as they say they are, it is much more instructive to identify the areas where users think collections are least adequate. The purpose of our survey was not to see whether scholars like their libraries-the shelves are already sagging under the weight of user surveys saying this is so-but to identify weaknesses as well as strengths. We also thought the relatively low rating of book collections for research-at all institutions, research universities as well as colleges-was a confirmation of what library spokesmen have been saying all along, that no university library can be self-sufficient today and that resource sharing is essential. And we said so specifically.

The most serious charge of slanting our interpretations is based on statements that we did not make. Epp and Segal write as follows:

"The survey authors interpreted the statistics when they affirmed that 'only' $77 \%$ of the scholars have one or more people in their department with whom they share research interests, and that 'only' $61 \%$ regularly ask someone in their department to comment on their work. Readers may be led to share the survey authors' conclusion that this is a deplorable situation where ' $40 \%$ have no one in their department to ask for comments on their manuscripts."”

We did not conclude that the situation is deplorable and we did not cite either figure $-77 \%$ or $61 \%$-in the text. Both appear in a table in which the column headings are neutral, and which indicate no judgment on our part regarding whether the percentages are high or low, good or bad.

The quoted word "only," which is inserted twice by our critics in this passage and which conveys the impression that we slanted the interpretation, does not appear anywhere in our discussions of the questions about sharing of research interests and commenting on papers written by colleagues. Our reporting was factual; we drew no inferences. Readers who have any doubts about what we said are invited to turn to the last full paragraph on page 6 of our report.

\section{What we left out and why}

The most detailed and indignant criticisms are directed at us for slighting important issues. The "most surprising" omission, in their view, is that we did not address the issue of preservation of deteriorating source materials: "Surely scholars are not indifferent to the fate of these irreplaceable materials," they say.

We agree, and indeed would go farther: we do not think it requires a survey to establish that fact. On this matter, we think Epp and Segal have confused the importance of the issue of preservation with the importance of asking scholars to answer questions about it.

There is not much to be learned from asking scholars whether they think the material in crumbling books should be preserved, and not much purpose in asking them whether they think the diethylzinc process for mass deacidification is the right way to go, or whether microform is the most appropriate medium for preservation.

With regard to preservation, the big need is to educate scholars about the threat to our recorded heritage and the role they might play in advancing the cause of preservation. That's what the National Enquiry tried to do a decade ago, what our office has tried to do in our newsletter, and what the $\mathrm{NEH}$ and the National Commission on Preservation and Access are doing. We thought the limited space in the questionnaire might be better devoted to asking scholars about matters on which they have had experience or on which they are well informed.

Scholars are, of course, in a position to render informed opinions on another issue that was not covered in our survey. We were criticized for failing to address matters of "institutional governance and academic powers." On this issue, the opinions of scholars are indeed worth getting. But we need to remind our critics that we were conducting a survey of "scholarly communication," not "higher education," and while matters of institutional governance no doubt have a bearing on scholarly communication, the link is less direct than it is to the issues that we sought to examine.

Epp and Segal seem to give little thought to the purpose of the survey and the fact that there is a relationship between the length of a questionnaire and the likelihood that it will be answered. Our list of omissions-questions that we wanted to ask but had to leave out-is far greater than theirs. To reduce the questionnaire to manageable length, we cut it by about 40 percent-from about 125 questions to 75 (many of them with multiple parts). The problem we had to face, in discussions with our consultant and advisory committee, was deciding how long the survey could be before it would get tossed into the waste basket. We think we pushed our luck by mailing out a 16-page questionnaire which, according to pretests, required $30-40 \mathrm{~min}-$ utes to fill out. We can agree to disagree on the specifics of what should be included, but we reject the implication that questions were omitted capriciously, without forethought.

We are also called to account for failing to recog- 
nize that scholars have been inconvenienced because they had to "travel to another city to get access to rare materials." But again, given the limitations on the length of the questionnaire, the issue is whether this aspect of the access problem is more important than the access questions we asked related to interlibrary lending, electronic searches and so on.

We were criticized on two occasions for failing to ask scholars whether they read Choice (Mr. Epp's journal) and Booklist. But as we stated clearly, the purpose of the question to which our critics referred was to probe the scope of respondents' reading habits outside their specialty-from general book review media to publications on science for the non-scientist. We were not surveying readership of book review publications aimed at librarians, such as Choice or Library Journal.

This does not exhaust our disagreements with our critics, but it probably exhausts the reader's patience-and the space allotted to us. Let us simply add that we do not want to suggest that we think our survey is above criticism. It has a number of limitations that we point out in our report, and, with hindsight, we can see a number of ways in which it could have been better. We simply believe that in general Epp and Segal have zeroed in on the wrong targets and in many instances have not fairly represented our purpose and results.

\section{Looking ahead}

In view of our response, readers may wonder whether there is a brick in the bouquet we toss now to Epp and Segal. There is not. We applaud them for doing, and doing very well, what no other commentators have done: to explore the implications of our data when the findings seem convincing and relevant. We are pleased that they did indeed find some of the results worthwhile, and, more importantly, that they were able to generate a kind of action agenda by drawing on the survey and on the ARL report, "The Changing Agenda of Scholarly Communication," which was discussed in less detail in the same article. No, the bouquet is genuine. On balance, we think their article is highly constructive, and we hope that it leads to further discussion and action.

\section{The authors respond:}

I wish to thank Herbert C. Morton for his response to our article. While not wishing to engage in a point by point response to his criticisms, one personal matter is worth noting. As a member of the American Philosophical Association I was one of the scholars chosen to participate in the survey. Suggestions by Mr. Morton that academic librarians failed to see the larger purposes of the survey are not deserved. JoAn Segal and I stressed our concerns for larger issues-such as academic governance-and we made an effort as well to give some indication of concerns that would be peculiar to a survey participant.-Ronald H. Epp, Managing Editor, Choice.

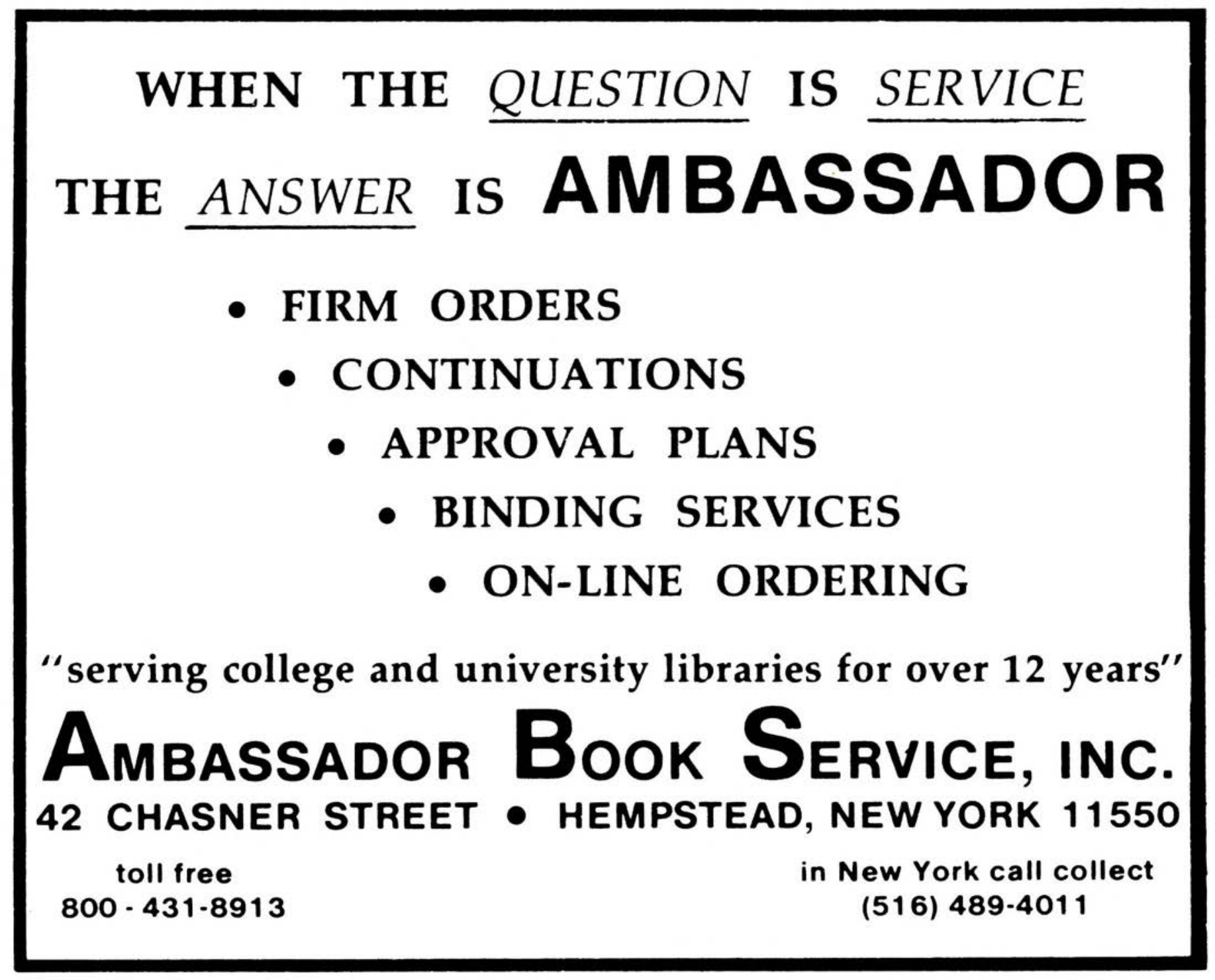

